FACULDADE DE CIÊNCIAS ECONô MICAS dA UFRGS
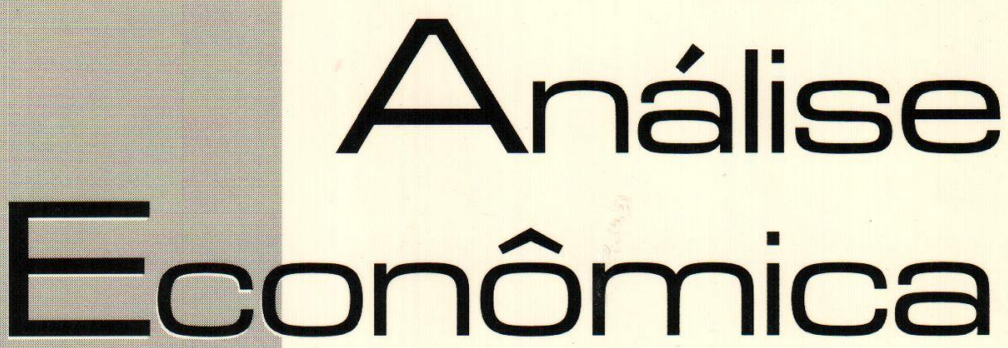

ESCOLHA DE PORTFÓLIO, INVESTIMENTO E NĀO. NEUTRALIDADE DA MOEDA

JOSÉ LUIS OREIRO

REFORMAS NA AROUITETURA FINANCEIRA INTERNACIONAL: NOVIDADES NO FRONT? ANDRÉ MOREIRA CUNHA

MERCOSUR'S CHANGE IN TRADE PATTERNS ANDRÉ FILIPE ZAGO DE AZEVEDO

O IMPACTO DA COMPOSICÃO SETORIAL, DOS FLUXOS INTRA-SETORIAIS E DA ABERTURA COMERCIAL NA PARTICIPAÇÁO DE MERCADO DAS EXPORTAÇÓES BRASILEIRAS

CLÉSIO LOURENÇO XAVIER E EMERSON FERNANDES MARÇAL

O EFEITO BALASSA-SAMUELSON E A PARIDADE DO PODER DE COMPRA NA ECONOMIA BRASILEIRA CLÁUDIO ROBERTO FÓFFANO VASCONCELOS

CICLOS Y FLUCTUACIONES FINANCIERAS: LA IRREGULAR DINÁMICA ECONÓMICA

SARY LEVY-CARCIENTE

O PENSAMENTO DE KARL POPPER: AS DIFERENTES INTERPRETACÓES DOS METODÓLOCOS DA CIENCIA ECONÓMICA

SOLANCE REGINA MARIN E RAMÓN GARCÍA FERNÁNDEZ

A EXPANSÃO DO ESCOPO TEMÁTICO DAS NEGOCIAÇÓES COLETIVAS DE TRABALHO CARLOS HENRIQUE HORN

EFEITOS DO CAPITAL SOCIAL E DO CAPITAL POLITICO NO DESENVOLVIMENTO ECONOMMICO SIMULAÇOES PARA PAISES E ESTADOS BRASILEIROS

RONALDO A. ARRAES, RICARDO CANDÉA S. BARRETO E VLADIMIR KÜHL TELES

O PROBLEMA DE RISCO MORAL NO MERCADO BRASILEIRO DE ASSISTÊNCIA MÉDICA SUPLEMENTAR LUCIANA PINTO DE ANDRADEE SABINO DA SILVA PÓRTO JÚNIOR

ANO

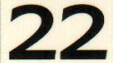

No 41

Março, 2004 
Universidade Federal do Rio Grande do Sul

Reitora: Profo. Wrana Maria Panizzi

Faculdade de Ciencias ECONOMICAS

Diretora: Prof Pedro César Dutra Fonseca

Centro de Estudos e Pesquisas Economicas

Diretor: Prof. Gentil Corazza

Departamento de Ciencias Económicas

Chefe: Prof. Ricardo Dathein

Curso de Pós-Graduação em Economia

Coordenador: Prof. Eduardo Pontual Ribeiro

Programa de Pó-Graduação em Desenvolvimento Rural

Coordenador: Prof. Jalcione Almeida

CONSElHo EDITORIAL:

Carlos G. A. Mielitz Netto (UFRGS), Eduardo A. Maldonado Filho (UFRGS), Eduardo P. Ribeiro (UFRGS), Eleutério F. S. Prado (USP), Eugênio Lagemann (UFRGS), Fernando Cardim de Carvalho (UFRJ), Fernando Ferrari Filho (UFRGS), Fernando de Holanda Barbosa (FGV/RJ), Flávio Vasconcellos Comim (UFRGS), Gentil Corazza (UFRGS), Giácomo Balbinotto Netto (UFRGS), Gustavo Franco (PUC/RJ), Jan A. Kregel (UNCTAD), João Rógério Sanson (UFSC), Joaquim Pinto de Andrade (UnB), Jorge Paulo Araújo (UFRGS), Juan H. Moldau (USP), Marcelo S. Portugal (UFRGS), Maria Alice Lahorgue (UFRGS), Paul Davidson (University of Tennessee), Paulo D. Waquil (UFRGS), Pedro C. D. Fonseca (UFRGS), Philip Arestis (Levy Economics Institut of Bard College), Roberto C. de Moraes (UFRGS), Ronald Otto Hillbrecht (UFRGS), Sabino da Silva Porto Jr. (UFRGS), Stefano Florissi (UFRGS) e Werner Baer (University of Illinois at Urbana-Champaign).

COMISSĀO EDITORIAL:

Eduardo Augusto Maldonado Filho, Fernando Ferrari Filho, Gentil Corazza, Marcelo Savino Portugal, Paulo Dabdab Waquil e Roberto Camps Moraes.

EDITOR: Prof. Fernando Ferrari Filho

Editor Adjunto: Prof. Gentil Corazza

SeCretária: Paulo Roberto Eckert

REVISÃO DE TEXTOS: Vanete Ricacheski

EdITORAÇÃo Eletrónca: Vanessa Hoffmann de Quadros

Fundador: Prof. Antônio Carlos Santos Rosa

Os materiais publicados na revista Análise Econômica são da exclusiva responsabilidade dos autores. É permitida a reprodução total ou parcial dos trabalhos, desde que seja citada a fonte. Aceita-se permuta com revistas congêneres. Aceitam-se, também, livros para divulgação, elaboração de resenhas e recensões. Toda correspondência, material para publicaçāo (vide normas na terceira capa), assinaturas e permutas devem ser dirigidos ao seguinte destinatário:

PROF. FERNANDO FERRARI FILHO Revista Análise Econômica - Av. João Pessoa, 52 CEP 90040-000 PORTO ALEGRE - RS, BRASIL Telefones: (051) 316-3513 - Fax: (051) 316-3990

Análise Econômica E-mail: rae@ufrgs.br

Ano 22, $n^{\circ} 41$, março, 2004 . Porto Alegre

Faculdade de Ciências Econômicas, UFRGS, 2004

Periodicidade semestral, março e setembro.

Tiragem: 500 exemplares

1. Teoria Econômica - Desenvolvimento Regional -

Economia Agrícola - Pesquisa Teórica e Aplicada -

Periódicos. I. Brasil

Faculdade de Ciências Econômicas,

Universidade Federal do Rio Grande do Sul. 


\title{
A Filosofia de Karl Popper: As diferentes interpretações dos metodólogos da Ciência Econômica
}

“É bom lembrar que nossa ciência ocidental - parece não haver outra - não começou colecionando observações sobre laranjas, mas sim formulando teorias ousadas sobre o mundo".

"Há apenas um ingrediente de racionalidade em nossas tentativas de conhecer o mundo:

o exame crítico das teorias".

"Em si mesmas, as teorias são suposições. Não sabemos; supomos"

Karl R. Popper

\begin{abstract}
Resumo: Procura-se fazer uma análise de três leituras da filosofia da ciência de Karl Popper (1902-1994) propostas por diferentes especialistas em metodologia da economia. Cada uma delas destaca diferentes aspectos de sua obra (falsificacionismo, análise situacional e diálogo crítico), como recomendação básica para o adequado desenvolvimento da $\mathrm{Ci}$ ência Econômica.
\end{abstract}

Palavras-Chave: metodologia econômica; racionalismo crítico e Karl Popper.

\begin{abstract}
The purpose of this paper is to consider three different readings of Karl Raimund Popper's (1902-1994) philosophy of science proposed by some economic methodologists. Each one of them stresses different aspects of Popper's perspectives (falsificationism, situational analysis and critical dialogue), as the proper basis for the adequate development of Economics.
\end{abstract}

Key-words: economic methodology, critical rationalism and Karl Popper.

JEL Classification: B-040.

\footnotetext{
${ }^{1}$ Mestre em Desenvolvimento Rural pela UFGRS; doutoranda do Programa de Pós-graduação em Desenvolvimento Econômico da UFPR. E-mail: solremar@yahoo.com.br

${ }^{2}$ Prof. do Programa de Pós-graduaçāo em Desenvolvimento Econômico da UFPR. E-mail: ramongf@ufpr.br
} 


\section{Introdução}

Karl Popper (1902-1994) nasceu em Viena, Áustria. Embora fosse um filósofo da ciência, sua obra teve grande repercussão fora do âmbito específico da filosofia, sendo seu impacto especialmente significativo na economia. Para Bruce Caldwell (1991), dentre os muitos fatores para a grande popularidade de Popper estão a sua clareza e sobretudo as suas perguntas certeiras sobre assuntos relevantes dentro da pesquisa científica.

$\mathrm{Na}$ economia, a obra de Popper mais conhecida é a Lógica da Descoberta Científica de 1934, publicada em inglês somente no final da década de 50 (quando Popper se encontrava morando na Inglaterra há mais de uma década) ${ }^{3}$.

Caldwell (1991) sugere que a filosofia da ciência de Popper tem sido interpretada pelos metodólogos da economia de duas maneiras, como se existissem duas pessoas diferentes ${ }^{4}$ : Popper ${ }_{N}$ (das ciências naturais) e Popper ${ }_{S}$ (das ciências sociais). Com essas duas visōes, Caldwell examina as suas influências na metodologia da economia e na história da ciência econômica, observando pontos de convergências e de divergências, assim como sua aplicabilidade. Indica que a perspectiva da metodologia da ciência econômica transita entre essas duas visões, uma vez que existem alguns que propōem que esta poderia ser vista como defendendo basicamente o falsificacionismo (Popper ${ }_{N}$ ), enquanto outros sugerem a análise situacional (proposto pelo Popper ${ }_{S}$ ) como sendo a metodologia adequada para as ciências sociais e especialmente para a economia.

O principal responsável pela apresentação do Popper falsificacionista na economia é Mark Blaug. Este autor é favorável ao falsificacionismo, desde que definido de um ponto de vista metodológico que considere as teorias e hipóteses como sendo científicas se e somente se suas previsões forem pelo menos em prin-

\footnotetext{
${ }^{3}$ Esse intervalo entre os escritos nos quais as idéias de Popper foram inicialmente propostas e a veiculação das mesmas em publicaçōes de maior impacto constitui um complicador quando o objetivo é delinear a filosofia de Popper.

${ }^{4}$ Esta argumentação de Caldwell tem como base um trabalho de Imre Lakatos (1979) no qual sugere a existência de três Poppers: Popper ${ }_{0}$, Popper ${ }_{1}$ e Popper ${ }_{2}$. O primeiro é o falsificacionista dogmático, na verdade, segundo Lakatos, inventado pelos críticos de Popper. O segundo é o falsificacionista metodológico ingênuo, e o último é o fasificacionista metodológico sofisticado (Lakatos, 1979, p. 224).
} 
cípio falseáveis. "Alcançar de forma completa o ideal da falseabilidade é o objetivo principal da economia" (Blaug, 1999, p. 34).

Para Wade Hands (1992), o falsificacionismo é mais conhecido dentro da economia, porém, quando estritamente interpretado, pode ser de pouco uso para o economista. Hands lembra, contudo, que o próprio Popper fez uma proposta que ele achava mais adequada para as ciências sociais (e especialmente para a metodologia) em outras obras posteriores, chamada análise situacional. O falsificacionismo parece inconsistente com a proposta de análise situacional de Popper para as ciências sociais. Porém, continua Hands, enquanto este Popper $\mathrm{r}_{\mathrm{s}}$ o da análise situacional, é praticamente desconhecido entre os economistas, parece muito aplicável na metodologia econômica, especialmente na análise microeconômica.

Outro corte foi proposto por Lawrence Boland (1994), segundo o qual existem duas visōes da filosofia da ciência de Popper, uma mais popular, centrada no falsificacionismo, e outra, embora menos popular, mais importante: o Popper do Diálogo Socrático (Popper D). Na visão do Popper Socrático predomina "a ênfase do papel crítico da racionalidade. Racionalidade é debate crítico - com a ênfase no debate. Popper as vezes chama isso de racionalismo crítico" (Boland, 1994, p.157). Nesta visão, o âmago da metodologia popperiana se encontraria na proposta de racionalismo crítico, também abordado por Caldwell.

Este artigo pretende apresentar e discutir as diferentes propostas e suas correspondentes interpretações do pensamento de Karl Popper na área da metodologia econômica. A partir do entendimento das diferentes interpretações da filosofia popperiana, pretendese fazer, em forma de consideraçōes finais, um contraponto, se houver, entre os três Popper propostos: o Popper ${ }_{\mathrm{N}}$ (falsificacionismo), que trata da filosofia da ciência em geral; o Popper ${ }_{\mathrm{s}}$ (análise situacional), que expõe uma lógica das ciências sociais; e, o Popper D (racionalismo crítico), que destaca a importância do debate críti$\mathrm{Co}$, desde que conduzido com racionalidade e mantendo o compromisso com a análise empírica. 


\section{Popper $_{N}$ (ciências naturais) e o monismo metodológico}

O objetivo central de Popper nos anos 30, através da publicação de $A$ Lógica da Pesquisa Científica, era enfrentar o positivismo lógico do Círculo de Viena. Esse positivismo era considerado por ele como uma matriz de dogmatismos, cuja ênfase estava em identificar a ciência como uma atividade estritamente indutiva. Ou seja, a partir de observações eram levantadas hipóteses e formuladas leis sobre fenômenos, procedendo depois à sua generalização e verificação. Popper se manteve fiel a esta perspectiva e, muitos anos depois, em 1983, refinaria esta crítica aos positivistas no seu Pós-Escrito à Lógica da Descoberta Científica: ORealismo e o Objetivo da Ciência (1997).

Para Popper (1997, p. 190), a aplicação do seu critério de demarcação (falsificacionismo), antes de buscar separar ciência de metafísica $^{5}$, como queriam os positivistas lógicos do Círculo de Viena, visava avaliar teorias e ajuizar suas pretensóes. Disso surgia a necessidade de um critério para um problema prático: decidir se uma certa teoria é aceitável por meio de argumentos empíricos. Tratavase, apenas, de examinar as condições de aceitação de uma teoria, frente a observações e experimentações empíricas, podendo ela resistir ao teste (ser corroborada) ou, caso contrário, ser refutada.

Popper não estava satisfeito com o critério de demarcação dos positivistas lógicos ${ }^{6}$, fundado no verificacionismo (Popper 1997, cap. II). Embora ainda não tivesse analisado a fundo o problema da indução de David Hume, Popper já observava na Lógica da Pesquisa Científica que o critério para justificar uma teoria científica empírica era a sua capacidade de testabilidade, refutabilidade ou

\footnotetext{
${ }^{5}$ Popper admite a influência constante da metafisica, inexistindo um critério seguro para verificar se uma proposição é ou não metafísica (p. ex., o atomismo de Demócrito). Se uma proposição puder ser testada, antes deve ser possivel falseá-la, caso contrário será confirmada, e não corroborada. Mesmo assim, esse critério não assegura se a proposição testável é ou não é metafísica. A terceira seção deste trabalho trata da posição metafísica explicitamente assumida por Popper.

" Popper distingue "critério de demarcação do significado" de "critério de demarcação entre ciência empírica, por um lado, e matemática pura, lógica, metafísica e pseudociência, por outro" (Popper, 1997, p. 191). O primeiro é identificado como o método verificacionista dos positivistas, que buscavam confirmar se uma teoria teria ou não significado (ou ser significante). O segundo corresponde ao seu método do falsificacionismo, que estabelece a possibilidade da teoria ser criticável (ou testável). Popper dava pouca importância ao primeiro critério, mas o último constituiu uma preocupação central em toda sua obra.
} 
falsificabilidade (Popper, 1997, p. 180). Ao invés de obter a confirmação da teoria pelos dados (verificacionismo), mais adequado seria propor um enunciado para falsificar a teoria e testá-lo nas observações e experimentações.

Uma teoria com possibilidade de ser falsificada pode ser caracterizada como científica. Logo, uma teoria que não pode ser testada com este critério, ou seja, não pode ser falsificada, não é tampouco científica, mas deve ser considerada como pertencente à lógica, matemática pura, metafísica ou pseudociência.

A intenção de Popper era somente decidir se alguma teoria era aceitável em termos científicos. Porém, o método falsificacionista foi interpretado como uma revisão do critério de demarcação dos positivistas lógicos, ou seja, um verificacionismo com nova roupagem. Para Popper (1997, cap. I), tal confusão decorre do indutivismo, então predominante entre os positivistas e os empiristas, para os quais a origem do conhecimento são os dados observáveis e experimentais. Contudo, se esses dados empíricos não falam por si, devem ser traduzidos a partir de uma prévia formulação racional. Então, como acredita Popper, a indução não pode ser considerada como origem do conhecimento.

Para Popper (1997, p. 62), David Hume propôs o chamado "problema da indução" que se referia à validação das regularidades tendo em vista, por um lado, o desconhecido (princípio da invalidade da indução), principalmente em relação ao futuro e, por outro, a convicção de que só tem validade a experiência (princípio do empirismo). Porém, como obter conhecimento diante das experiências desconhecidas, notadamente as do amanhã? Tal dúvida compromete a verdade da existência de regularidades. Hume, então, conclui que a indução é racionalmente inválida. E, diante da constatação de que tudo provém da experiência, confiou no hábito, e não na razão.

Popper acrescenta uma outra proposição ao problema da indução: o princípio do racionalismo crítico, visando resgatar a razão excluída por Hume (Popper, 1997, p. 64). A indução é inválida, como pretende Hume: não tem valor lógico, tendo em vista a impossibilidade de se apreender todas as possibilidades de ocorrência dos eventos. Porém, seguindo Popper, Hume deu um valor factual e não apenas lógico para a indução, cujo emprego poderia ser justificado através do hábito (aprendemos com as repetições, com as re- 
gularidades que aparecem sucessivamente), do que decorreria, por indução, embora inválida, que os fatos da vida ensinam os seres humanos.

Popper considera um mito o fato da indução, ainda mais que o princípio do racionalismo crítico representava um acréscimo em compatibilidade e consistência nos passos do problema da indução de Hume em contraposição ao "hábito"7. Pelo racionalismo crítico, teorias são suposições, conjecturas ou hipóteses. As regularidades são firmadas pelo método da tentativa e erro, de conjectura e refutação, ou aprendizagem a partir dos nossos erros; regularidades não são obtidas por acumulações ou associações de observações. Diante disso, é errando (testando) que se aprende e se faz ciência.

O falsificacionismo de Popper não visa dar um valor factual para observações e experimentações (mito da indução), mas exclusivamente um valor lógico: o de propor contra-argumentos passiveis de testes.

Se o falsificacionismo é uma questão lógica, então pode ser válido para todas as ciências ("monismo metodológico"). Este é o critério de demarcação de Popper que difere dos positivistas ao rejeitar o indutivismo, assumindo uma preferência pela dedução. Ele apenas requer que as deduçōes sejam testáveis, de modo a serem corroboradas ou falsificadas, pois se objetiva o conhecimento racional crítico, conjectural, e não o conhecimento ideal.

A formulação da visão do Popper $_{N}$ mostra o falsificacionismo como método lógico que empreende testes para as teorias. Na crítica dessa visão popperiana, muitas vezes se tem em vista as inconsistências lógicas do método, como no caso da formulação de Duhem-Quine ${ }^{8}$.

Quando Hands (1992) formula a dificuldade de aplicação do critério do falsificacionismo na economia, refere-se apenas aos aspectos lógicos. Também tece algumas considerações sobre o pro-

\footnotetext{
7 Os passos do problema de Hume, ou o limite até onde a lógica alcança, é o que segue (Popper, 1997, p. 63): (i) confia-se na existência de regularidades e de leis da natureza; (ii) mas não podemos ter experiência de muitas coisas, desconhecidas e localizadas no futuro; (iii) por outro lado, só podemos conhecer com essa experiência. Popper acrescenta (iv) o princípio do racionalismo crítico, dando consistência e compatibilidade de (i) a (iv), pois resolve a aparente contradição entre (ii) e (iii). Hume decide, com relação a esta aparente contradição, que tudo é (iii). Mas, conclui Hume, já que a indução é racionalmente inválida, confia-se no hábito e não na razão.

${ }^{8} \mathrm{O}$ problema Duhem-Quine expōe que nenhuma hipótese é testada isoladamente, mas sempre junta com pressupostos auxiliares e descrições de condições iniciais (Zahar In: O`Hear, 1997, p. 58). Assim, uma hipótese falsificada pode determinar a falência de todo o sistema teórico, algo que não acontece freqüentemente. Para uma defesa do falsificacionismo diante dessa crítica, ver Zahar in: $\mathrm{O}^{\prime}$ Hear, 1997
} 
blema da verdade, sobre o realismo objetivo e sobre a indisposiçāo do cientista econômico quanto a teorias testáveis independentemente da teoria então em voga, temas estes que ultrapassam o âmbito do falsificacionismo lógico.

Devem ser considerados os problemas da lógica pura ou do esquema lógico da explicação (explanação) - como destaca Hands, os problemas duhemiano, da inexistência de base empírica, da corroboração de teorias por trivialidade, e da teoria independentemente testável - , buscando-se uma tentativa de solução, sempre no campo da lógica, quando então o falsificacionismo pode ter sua aplicabilidade na teoria econômica.

Caldwell (1991) afirma que T. W Hutchison, J. Klant e M. Blaug são os maiores defensores do falsificacionismo na economia, mas como critério de demarcação. Por mais que Popper insista que o método falsificacionista pretendia avaliar teorias e ajuizar suas pretensōes, este foi interpretado como critério de demarcação entre ciência e pseudociência.

Segundo Caldwell (1991), Hutchison foi o primeiro a introduzir a testabilidade como um critério para distinguir entre ciência e pseudociência, na obra The Significance and Basic Postulates of Economic Theory, publicada originalmente em 1938. Ainda conforme Caldwell, Hutchison, Blaug e Klant são críticos da proposta de Ludwig von Mises de que a economia é a ciência da ação humana, por entenderem que esta proposta propõe uma teoria econômica não-falsificável, sendo, portanto, dogmática9. Todavia, as dificuldades de falsificar o marxismo clássico e os institucionalistas americanos, por exemplo, levam Blaug e Hutchison a concluírem que é difícil falsificar teorias econômicas. Caldwell observa que também Friedrich Hayek achava difícil falsificar teorias econômicas, tendo em vista a complexidade dos fenômenos que focalizam. Predomina o entendimento do falsificacionismo como critério de demarcação entre ciência e não-ciência, que permite desconsiderar algumas teorias econômicas dogmáticas (não falsificáveis), uma vez que elas são estabelecidas com base em princípios para os quais não é con-

\footnotetext{
${ }^{9}$ Segundo Blaug (1999, p.129), o enunciado de praxeology (ciência da ação humana) de Mises postula que a ação individual propositada funciona como um pré-requisito para se explicar todo o comportamento, incluindo-se, o comportamento econômico. Isto não seria satisfatório como pedra angular para uma teoria verdadeiramente científica, pois não seria falsificável.
} 
cebível uma situação na qual possam vir a ser considerados falsos. Boland (1994) também encontra dificuldade em aplicar o falsificacionismo na ciência econômica. A economia não parece se adequar ao método de escolher a melhor teoria (avaliar e justificar), dentre outras teorias competidoras, não só pela falta de competição, mas pela pouca mudança que ocorre na teoria econômica.

Para Popper (1997, p.180), o entendimento errôneo do seu método de avaliar e julgar teorias testáveis é decorrente da falta de ligação entre o problema de demarcação e o problema da indução, somente apresentado no Pós-Escrito em 1983. Popper com seu critério falsificacionista procurou um método de testar uma teoria e não de procurar verificaçōes, como sugeriam os positivistas ${ }^{10}$. Para Popper, o falsificacionismo era antes uma questão de lógica do que uma preocupação essencialmente empírica.

Mas o problema do falsificacionismo também deve ser observado com a inserção da idéia do racionalismo crítico. Para Blaug (1994), alguns tépidos popperianos como Caldwell, Boland e Hands, depois de terem discutido algumas objeções à visão metodológica de Karl Popper, tenderam em favor do "racionalismo crítico" como a essência de Popper. Antes, contudo, do exame do racionalismo crítico, bem como do estabelecimento de princípios racionais (seção 4), que pode ser considerada a emenda que Popper e outros fizeram ao falsificacionismo (Caldwell, 1991 e Hands, 1992), é interessante firmar algum entendimento sobre a análise situacional, ou o chamado Popper ${ }_{s}$ das ciências sociais, visto por Caldwell e Hands como o mais adequado para a metodologia econômica.

\section{O Popper $_{S}$ e a análise situacional}

Quando se trata das ciências sociais, Popper introduz a lógica da situação. Na vigésima-quinta Tese da Lógica das Ciências Sociais (Popper, 1992) é apresentada a análise situacional:

${ }^{10}$ Sobre a assimetria entre verificação e falsificação, ver Popper (1997, p. 97-204).

"Segundo Popper, o falsificacionismo permite apresentar um critério objetivo para as ciências naturais, mas faltava uma proposta objetiva para as ciências sociais. Diante de limitações do método falsificacionista no ambiente social (por ex. a maior dificuldade na realização de testes controlados), a lógica da situação seria o método objetivo das ciências sociais. 
A investigação lógica dos métodos de economia política conduz a um resultado aplicável à totalidade das ciências sociais. Este resultado demonstra a existência, nas ciências sociais, de um método puramente objetivo ${ }^{11}$, que se poderá designar por método compreensivo-objetivo ou por lógica da situação" (Popper, 1992, p. 83, grifos no original).

A investigação lógica na "economia política" (à qual Popper se refere sem, infelizmente, especificar o que exatamente entende como tal) mostra a possibilidade de um método puramente objetivo (método compreensivo-objetivo), sem recorrer a idéias psicológicas ou subjetivas, que pode ser aplicado à totalidade das ciências sociais. Tal método consiste na análise da situação do indivíduo, na busca de explicar a ação a partir da situação. Para Popper, sempre que um indivíduo age, o faz seguindo um objetivo definido e de acordo com algum conhecimento da situação. Fatores aparentemente psicológicos, tais como desejos, impulsos, recordações e associações, são convertidos em fatores situacionais.

As ciências sociais devem ser constituídas pela lógica situacional, onde os desejos são convertidos em fins objetivos; recordaçōes ou associações em dotação de teorias ou informaçōes. No âmbito do método objetivo, não se recorre ao psicologismo ${ }^{12}$. E isto especificamente quanto à lógica do conhecimento das ciências sociais.

Hands (1992) constata a aplicabilidade da lógica situacional na economia, afirmando que se trata do método da microeconomia (e também da macroeconomia baseada em microfundamentos).

A análise situacional é o que em economia se conhece por conceito de escolha racional, isto é, a visão de que o comportamento econômico é simplesmente o comportamento maximizador individual sujeito a restrições, e na verdade Popper declarou 'análise situacional' ser uma generalização do método da análise econômica (Blaug, 1994, p.112).

Segundo a análise situacional, preferências, tecnologias e restrições (preços, renda, etc.) mostram a situação do agente e sua

12 O psicologismo é entendido como a doutrina de que todas as leis da vida social devem reduzirse, em última instância, às leis psicológicas da "natureza humana". Para mais detalhes ver Popper (1993) [1934] A Lógica da Pesquisa Científica, p. 31-32, Popper (1974) [1945] A Sociedade Aberta e seus Inimigos, cap. 13 e 14, Popper (1995) [1967] "O Princípio de Racionalidade" e mais adiante, nesta seção. 
motivação (maximização da utilidade). Essa situação é analisada segundo a dedução de um comportamento (compra mais ou menos, produz mais ou menos, etc.) que, quando apropriado, é matematizável na teoria econômica. Finalmente, fixa-se o princípio racional, segundo o qual os agentes atuam apropriadamente (racionalmente), dadas as situações analisadas. Este esquema lógico parece ser o da análise situacional. No entanto, permanecem problemas como o da escolha da teoria do comportamento adequado, bem como da discussão crítica da própria racionalidade.

Para caracterizar o sentido de objetividade, amplia-se a análise para a teoria do conhecimento científico. Popper inicia a Lógica das Ciências Sociais tomando o antagonismo entre saber e não-saber ${ }^{13}$, para chegar à seguinte tese:

(Quarta Tese) Na medida em que é possível dizer, de um modo geral, que tanto a ciência como o conhecimento começam em algures, então é igualmente válido o que se segue: o conhecimento não parte de percepções, de observações, nem da recolha de dados ou de fatos, mas sim de problemas. Sem problemas não há saber, como não há problemas sem saber (Popper, 1992, p. 72).

Com isto, exclui-se do sentido de objetividade o conhecimento através de dados da observação e da experimentação. Todo o nosso conhecimento parte de um problema, mesmo que seja algo surpreendente e novo que apareça como dado observável. Então, o método, válido tanto para as ciências naturais quanto para as ciências sociais, é tentar resolver os problemas (Popper, 1992, p. 73, Sexta Tese). Diante disso, propõe-se uma solução que será o objeto de crítica. Se a tentativa de resolver não resiste à crítica, a solução proposta ainda não tem rigor científico. Se resistir à crítica, a teoria é aprovada momentaneamente, pois se deve procurar outro aspecto para ser criticada. Se refutada, procura-se outra tentativa de solução, novamente exposta à crítica. É a tentativa de solução do problema sob controle rigoroso da crítica: o método da tentativa e erro. Assim, a

${ }_{13}$ Popper expõe a questão do saber na primeira tese e a do não-saber na segunda tese. $\mathrm{Na}$ terceira tese sugere a necessidade de uma teoria do conhecimento esclarecer as relações entre o saber e o reconhecimento do não-saber que satisfaça as duas primeiras teses (Popper, 1992, p.71-72). 
objetividade do método crítico - a objetividade da ciência - é considerar toda teoria criticável e toda crítica dotada de instrumentos lógicos objetivos.

No caso das ciências sociais, a "teoria da objetividade científica", a "própria sociologia do saber", que permite eliminar da análise aspectos da "posição social ou ideológica do investigador" só pode ser explicada:

... através de determinadas categorias sociais, como por exemplo: competição (tanto entre os cientistas, individualmente, como entre as diversas escolas); tradição (nomeadamente, a tradição crítica); instituições sociais (como sejam, publicações em diversos periódicos concorrentes; debates em congressos); poder estatal (nomeadamente, tolerância política face a debates livres) (Popper, 1992, p. 78, Décima terceira Tese).

As contraposições de idéias ocorrem no momento do debate crítico, no qual devem ser problematizadas e obterem propostas de solução, distinguindo problemas científicos de extracientíficos. Tal situação ocorre tanto nas ciências naturais quanto nas ciências sociais. Popper, pretende firmar a idéia de que a objetividade da ciência é uma questão social da discussão científica "... da sua colaboração mas também das guerras entre si" (Popper, 1992, p. 78) e não uma questão individual. A ideologia e posição social do investigador surgem no debate crítico e, ao longo do tempo, perdem a importância para o debate exclusivamente científico.

Popper discute seu método crítico com a negação do naturalismo metodológico. "É o caso, por exemplo, do naturalismo ou cientificismo metodológico, mal organizado e equivocado, que exige que as ciências sociais recorram, ao fim e ao cabo, às ciências da natureza para apreenderem o que é o método científico" (Popper: 1992, p.74).

O método de Popper permite distinguir valores científicos de não-científicos através da discussão crítica, enquanto que o naturalismo pretende que os cientistas se desfaçam de seus valores. Além disso, enquanto, em Popper, a tentativa de solução (dedução) é o objeto (da crítica), no cientificismo metodológico se procuram observaçōes e medições, apenas se aproximando do objeto científico, para depois generalizar (indução). $\mathrm{O}$ argumento negativo recai no problema da indução, mas agora com agravantes na dificuldade de se obter dados e medidas de fenômenos sociais, bem como na dificuldade de se obter objetividade nas ciências sociais, caso o cientista esteja mais ou menos suscetivel a valores. 
A crítica de Popper permite estabelecer outro tipo de objetividade, válida para todas as ciências: enxergar os problemas como objetos. Isto possibilita também a discussão sobre valores, escolhendo aqueles que podem ser considerados puramente científicos (a verdade, a inventividade, a capacidade de esclarecimento, a simplicidade, a precisão), diferenciando-os dos valores não-científicos, como interesses não inerentes à procura da verdade (interesses de, por exemplo, bem-estar, desenvolvimento industrial, enriquecimento pessoal). Popper mais uma vez critica o psicologismo como base das ciências sociais, mas não descaracteriza a existência de valores (científicos e não-científicos) que devem ser discutidos entre os cientistas. Alerta os cientistas sociais ao afirmar que aceitar as motivações psicológicas como fundamentos das ações e condutas humanas pode conduzir o cientista para a idealização da origem desses fundamentos, com o risco dessa origem ideal se tornar a força determinante das açōes sociais. O que Popper quer enfatizar é que, na maioria das situaçōes sociais, existe um elemento de racionalidade. Porém, com isso, Popper não quer dizer que todas as ações humanas são racionais, mas que existe a possibilidade da descoberta de um fundamento racional que informe e justifique as ações dos seres humanos ${ }^{14}$.

Dentro de uma argumentaçăo positiva na defesa do seu método crítico, Popper enfatiza que o objetivo da ciência é a explicação satisfatória do que aparece e impressiona (Popper, 1997, cap. 15). Esta explicação é satisfeita na relação entre os explicans (as premissas) e o explicandum (as conclusōes). A associação lógica entre os explicans e o explicandum constitui o esquema lógico da explicação (Popper, 1992, p. 81). Os explicans precisam implicar logicamente o explicandum, ser conjecturados verdadeiros, e, se não for possível tomá-los como aproximações da verdade, então devem ser independentemente testáveis. Aqui retorna o critério de demarcação, o falsificacionismo, na importância de não se tomar proposiçōes ad hoc, mas teorias independentes e testáveis, tendo em vista o avanço científico. A não ser nos casos de leis universais da natureza, como

\footnotetext{
14 Popper refere-se à racionalidade em dois sentidos: existe a racionalidade como atitude pessoal expressa pela disposição de admitir criticamente os erros e, portanto, corrigi-los. Porém, a expressão "principio de racionalidade" para qualificar as açōes humanas não quer dizer que os homens sempre adotem uma atitude racional diante dos problemas que enfrentam. $O$ princípio de racionalidade é mais um princípio mínimo que anima a todos os modelos situacionais explicativos. Este princípio pode ser resumido como a adequaçāo de uma ação a um problema situacional. (Popper, 1995, p. 391-92).
} 
explicans, que, pela riqueza de conteúdo, permitem testes independentes de proposições que não são ad hoc. Então, o avanço científico ocorre em direção a teorias de conteúdo cada vez mais rico, mais universais, e até mais exatas.

Popper acredita numa explicação suprema, de conteúdo rico para testes, o que ele denomina de essencialismo modificado ${ }^{15}$. Qualquer explicação pode ser melhorada por uma teoria ou uma lei de maior universalidade. As falsificações nos ensinam o inesperado, permitindo a ocorrência de choques com explicaçōes alheias, e que podem mudar em muito, dependendo do poder explicativo da teoria, nossa visão de mundo (Popper, 1997, p. 156).

Em resumo, a lógica situacional pode ser considerada como o método lógico das ciências sociais sugerido por Popper, enquanto o seu método crítico pertence à metodologia das ciências (sociais e naturais). De uma forma mais abrangente, a seleção de problemas faz parte da teoria do conhecimento ou da lógica do conhecimento, e o falsificacionismo, por sua vez, pertence à lógica pura e dedutiva.

Popper ensina que, para premissas verdadeiras e inferência válida, a conclusão deve ser verdadeira; porém, para conclusão falsa, de inferência válida, não é possível que todas as premissas sejam verdadeiras (Popper, 1992, p. 80, Décima Sétima Tese). A possibilidade de deduzir uma possível conclusão falsa é reduzida através da crítica racional, e a conseqüência lógica de uma conclusão falsa é a refutação da asserção (de pelo menos uma das premissas). Para Popper (1992, p. 80, Décima Nona Tese), teorias são sistemas dedutivos como tentativas de explicação e tentativas de solução de problemas, com crítica às pretensões à verdade. A racionalidade consiste em demonstrar que a pretensão à verdade é falsa: aprende-se com erros (Popper, 1992, p. 80, Vigésima Tese).

O Popper ${ }_{N}$, que agora pode ser visto como fundamentado em aspectos lógicos, diferencia-se do Popper $_{S}$ quando se expõe os aspectos psicológicos - as valorizaçōes do cientista, o amor à verda-

\footnotetext{
is Popper não acredita no essencialismo metodológico, que responde e pergunta o que é? (caso das definiçōes) (ver Popper, 1974, p. 15-28 e 301-302, Popper, 1997, p. 155 e 270-271), nem no instrumentalismo (ver Popper, 1997, p. 134-150 e 155). Para Popper, não existe um termo exato ou termos tomados precisos por definições precisas. Identifica-se o instrumentalismo na proposta para a metodologia da ciência econômica de Friedman (1981). Popper critica o instrumentalismo diferenciando teorias científicas de regras de computação (os instrumentos), e, principalmente, pelo fato de nāo se analisar a verdade ou falsidade dos instrumentos, ou seja, a validade dos procedimentos e técnicas.
} 
de, a defesa do sistema teórico e como base das ciências sociais - à crítica. Diante disso, Popper sugere a crítica racional, que envolve aspectos puramente lógicos, e, no caso das ciências sociais, a necessidade de considerar conceitos sociais (não-psicológicos) como o entorno da ação e dotação de conhecimento do individuo. Disso resulta que, dentro de um mundo físico com ações próprias das ciências naturais, reconhece-se um mundo social caracterizado por ações individuais e institucionais, um mundo com indivíduos e instituiçōes sociais, exposto por uma lógica situacional.

Hands (1992) verifica um paradoxo no fato de a metodologia econômica ter focalizado mais a visão falsificacionista do que a análise situacional, pois este é o método de Popper para as ciências sociais. Porém, a análise situacional seria exemplificada através das análises feitas na microeconomia, eis que baseada num princípio de racionalidade estabelecido (os indivíduos agem com uma razão econômica), em uma dada situação social.

Popper, no artigo O Princípio de Racionalidade, publicado pela primeira vez em 1967, estabelece que as ciências sociais operariam com o método de construir situações em condiçōes típicas. Por meio da análise situacional, as situações sociais típicas são transformadas em modelos. O erro, segundo Popper, está em animar o modelo social com as leis da psicologia humana. Então, ele sugere a fixação de um princípio de racionalidade que seria um postulado metodológico e não uma proposição empírica ou psicológica, onde: “ Os agentes sempre atuam de maneira apropriada à situação em que se encontram" (Popper, 1995, p.387). Mas, "utilizamos o princípio de racionalidade simplesmente como uma boa aproximação à verdade, reconhecendo que nāo é verdadeiro, senão falso" (Popper, 1995, p.390).

A economia política, como já dito por Popper, caracteriza-se em exemplo de um método para a investigação lógica das ciências sociais, com base no princípio de racionalidade e dentro da lógica da situacional. No entanto, resta a questão de se esse princípio de racionalidade pode ser falsificado (testável), segundo o método popperiano. A fixação de um princípio de racionalidade, como uma lei da natureza da qual decorrem os resultados, depende da crítica, mas também da metafísica. Nesse passo, Popper propōe o realismo objetivo como o método objetivo das ciências ${ }^{16}$.

\footnotetext{
${ }^{16}$ A ser desenvolvido na próxima seção.
} 
A análise situacional não pode ser vista apenas como o único método das ciências sociais. Os princípios e pressupostos desta estão situados em uma lógica mais abrangente, a que inclui também as ciências naturais, qual seja, a metodologia das ciências como sendo o método da discussão crítica. Diante disso, o falsificacionismo caracteriza-se como um critério forte para ajuizar se uma teoria é testável e aceitável como científica.

Para Caldwell (1991, p.13), o método da lógica situacional ou análise situacional é estudar as repercussões sociais não-intencionais de ações humanas intencionais, podendo ser o único método de exposição das ciências sociais. A tarefa das ciências sociais não é profetizar sobre problemas da sociedade ${ }^{17}$.

Contudo, para Caldwell, o estabelecimento do princípio racional no lugar das leis universais é problemático. Caldwell sugere um "marco zero" - o postulado de que os agentes atuam apropriadamente para suas situações - como na teoria microeconômica tradicional. Trata-se de um princípio metafísico que não é verificável, nem falsificável, tampouco refutável empiricamente. Portanto, igualmente ao caso das leis universais que estimulam modelos na ciência natural, o princípio racional anima as ciências sociais e, conseqüentemente, a ciência econômica.

A fixação de um princípio permite resultados então considerados científicos. Se tal princípio resultar num rico conteúdo, próprio para a testabilidade, a falsificação e a refutabilidade, pode ser prontamente aceito como racional. Porém, este racional não é obtido dos dados observáveis e experimentáveis (do indutivismo), mas do racionalismo crítico, como se expõe na próxima seção.

\section{O Popper $_{D}$ e a discussão crítica}

Uma discussão crítica, com base racional, travada em ambientes onde se pode identificar algo como um "estado do debate científico atual", é a proposta de diálogo socrático do Popper D $^{\text {. Porém, tal }}$ visão foi elaborada por Boland (1994) e não mencionada explicitamente por Popper.

${ }^{17} \mathrm{O}$ que, por sinal, é um dos temas reiterados na obra de Popper, destacando-se a esse respeito "A Miséria do Historicismo" no qual Popper questiona frontalmente a possibilidade de se fazer grandes previsôes em Ciências Sociais. 
No Pós-Escrito da Lógica da Descoberta Científica (1982), Popper salienta que sua visão poderia ser entendida como "falibilismo e abordagem crítica". Por falibilismo se entende que não existe certeza do conhecimento ou verdade, pois todo conhecimento é conjectural e, por abordagem crítica, ele quer demonstrar o que justamente foi denominado de racionalismo crítico. "Todas as teorias científicas estariam abertas ao criticismo, particularmente com referência aos problemas com os quais as teorias em questão estavam designadas a resolver" (Blaug, 1994, p.112).

A idéia socrática do não-saber toma aqui outro rumo: a cada nova descoberta, surgem novos problemas, reforçando a consciência de que apenas se conseguiu aproximar da verdade, ou de que unicamente se fez uma tentativa de resolver o problema (Popper, 1992, p. 71, Segunda Tese). Mas, ao mesmo tempo, temos consciência de saber algo, sugerindo a aparente contradição entre o saber e o não-saber. Assim, o debate crítico é interminável, diferente da proposta socrática de saber que não sabe. Para Popper, o saber e o nãosaber são conciliados no problema (origem do conhecimento) que é desafiado pelo debate crítico: por isso a recomendação de um procedimento metodológico de algo como o diálogo socrático.

Na visão do Popper socrático, a ciência é mais um processo em estado de fluxo constante, do que uma postura estabelecedora de verdades estáveis não sujeitas à revisão. Não há método infalível, nem autoridade, nem fatos inquestionáveis. "A ciência é pensamento cientifico sem método científico" (Boland, 1994, p.162).

A discussão crítica deve ser vista sob as perspectivas do racionalismo crítico e do realismo objetivo propostos por Popper para mostrar a sua visão de mundo. Num aspecto lógico, para compreender as interações do mundo físico com o mundo social, usa-se o falsificacionismo e o estudo da lógica situacional, bem como os conceitos lógicos de aproximação da verdade e tentativa de solução de problemas ${ }^{18}$.

\footnotetext{
${ }^{18}$ Segundo Popper, a nossa realidade consiste em três mundos ligados entre si (A palavra Mundo nāo significa Universo ou Cosmos, mas apenas partes deste). Estes três mundos são: o Mundo físico, Mundo 1, dos corpos e dos estados, fenômenos e forças físicas; o Mundo psíquico, Mundo 2, das emoções e dos processos psíquicos inconscientes; e o Mundo 3 dos produtos intelectuais (Popper: 1992, p. 21-22). A diferença entre os três mundos popperianos torna-se mais clara com a consideração sobre seus modos de existência: "o Mundo I é determinado pela materialidade fisica das coisas; o Mundo 2 existe em nossas disposições e reações psicológicas e o Mundo 3 não está em lugar algum" Neiva (1999, p. 23).
} 
$\mathrm{Na}$ abordagem do Popper $_{\mathrm{D}}$, contudo, o método do falsificacionismo pode ser caracterizado como uma condição lógica requerida pelo racionalismo crítico, e a racionalidade continua sendo essencial, porém somente enquanto um aspecto da crítica.

Popper entende que o racionalista se esforça por tomar decisões, trabalhando com argumentos. Difere do que ele denomina falso racionalismo, caracterizado por entender o mundo a partir da construção de máquinas gigantescas e mundos sociais utópicos. Enquanto que o verdadeiro racionalista procura soluções para os problemas presentes, o falso racionalista já tem as respostas prontas.

Estudando uma situação em microeconomia (teoria do consumidor), podemos ver as diferenças de abordagens entre a análise situacional e o diálogo socrático. $\mathrm{O}$ economista, ao olhar essa situação na primeira perspectiva, destaca a busca da maximização da utilidade frente um orçamento limitado e preços existentes. A diferença, para a lógica do Popper socrático, é que os economistas centrar-se-iam no papel do consumidor como sendo o de um indivíduo que tenta resolver um problema de escolha.

O racionalismo crítico consiste em defender racionalmente uma preferência, ou uma crença racional, ou teorias verossímeis, sabendo-se que na discussão crítica a crença pode ser abandonada. Se aqui surge um novo conflito com o falsificacionismo (na defesa racional da crença), observe-se que Popper agora trata do que pode ser racional, e de que o método é o racional.

Popper recorre aos quatro problemas da indução (ou fases da sua discussão, ou estágios do argumento) (Popper, 1997, p. 81-106), para apreciar o seu racionalismo crítico:

$\left.1^{\circ}\right)$ como distinguir teorias boas de teorias ruins: o problema prático de método;

$\left.2^{\circ}\right)$ como acreditar nos resultados da ciência: o problema da crença sensata;

$\left.3^{\circ}\right)$ como saber que o futuro vai ser como o passado: o problema do amanhã;

$\left.4^{\circ}\right)$ como saber se existem regularidades na natureza: o problema das leis universais verdadeiras.

As três primeiras fases já foram tratadas nas seções anteriores, pois correspondem à discussão lógica, metodológica ou epistemológica. Popper resume essa discussão: 
... eu substituí o problema 'Como é que sabe? Qual é a razão, ou a justificação, da sua asserção?' pelo problema: 'Por que é que prefere essa conjectura a conjecturas competidoras? Qual é a razão da sua preferência?'

Ao passo que a minha resposta ao primeiro problema é 'não-sei', a minha resposta ao segundo é que, regra geral, a nossa preferência por uma teoria mais bem corroborada será defendida racionalmente pelos argumentos que tiverem sido usados na nossa discussão crítica, incluindo, é claro, a discussão dos resultados dos testes. São esses os argumentos dos quais o grau de corroboração é suposto dar um relato sumário (Popper, 1997, p. 98, grifo no original).

Resolvido o problema da indução já nas três primeiras fases, resta o quarto que é metafísico: leis universais são irrefutáveis. Popper parece assumir sua posição de realista objetivo para acreditar que exista uma lei da natureza verdadeira, mas não acreditar numa causalidade universal.

O realista objetivo, segundo Popper, acredita que o conhecimento, sempre conjectural, é objetivo pois visa às coisas fora de nós, acreditando que aprendemos com fenômenos externos. A doutrina idealista é diferente por considerar a idéia de mundo como uma idéia nossa, de cada um. Popper alerta para a existência de outros conhecimentos científicos além do nosso; todos os indivíduos têm acesso ao conhecimento objetivo externo.

A base subjetiva, quando se considera que os sentidos humanos primeiro percebem, não precisa ser considerada, pois, desde o início, Popper sugere que se está no campo da intersubjetividade ao dar e receber propostas e ao desenvolver uma crítica racional (Popper, 1997, p. 112). O caráter hipotético do "conhecimento científico" e o caráter crítico de toda discussão racional permitem a combinação do realismo metafísico com o empirismo.

O conhecimento objetivo, então, é tomado como um tipo de instituição social, como resultado das ações humanas não-intencionais. $\mathrm{O}$ conhecimento subjetivo pode ser tomado como psicológico ou biológico. Popper entende que o empirismo tradicional pretende recolher os dados com os sentidos e acumulá-los (por repetição) como se fosse o nosso conhecimento. No entanto, nada é nos dado como base do conhecimento: não há dados não interpretados.

Nosso conhecimento, conforme Popper, é ação e reação na intersubjetividade. A supremacia concedida por Popper à investigação científica está relacionada com a noção de que a ciência tem 
pouca relação com fatores psicológicos ou subjetivos. O conhecimento científico é caracterizado pelo seu método: "a ciência é testável e criticável intersubjetivamente; sua eficácia resulta de um controle racional e objetivo que dispensa convicçōes subjetivas" Neiva (1999, p.84). A racionalidade decorre dos resultados dos testes, das críticas dos prejuízos, das conjecturas; ela é obtida no campo da intersubjetividade mediante discussão crítica.

$O$ realismo verdadeiro tem grandes afinidades com o conhecimento conjectural obtido nas discussões críticas, pois o realismo tem mais força lógica do que o idealismo, uma vez que o seu produto é falsificável. O idealismo, para Popper (1997, p. 125), padece do problema de encontrar uma explicação para tudo, impedindo, muitas vezes, a possibilidade de discussão crítica.

O diálogo socrático $\left(\right.$ Popper $_{\mathrm{D}}$ ) considerado por Boland, mais sofisticado graças à introdução das questões metafísicas relativas ao racionalismo e ao realismo (visão de mundo), aparece como a abordagem mais relevante para compreender a visão científica proposta por Popper. Ela deve manter, porém, a ênfase nas possibilidades lógicas de falsear teorias e nas investigações da lógica da situação.

Boland sugere esta visão para o cientista econômico. Assim, ao falsificacionismo restaria um papel menor, enquanto seria enfatizado o papel crítico da racionalidade. A ciência seria um caso especial de diálogo socrático, onde aprendemos com a eliminação dos erros diante da crítica. Sob esta visão de Popper, conforme enfatiza Boland (1994, p.158), pode não haver uma resposta para toda pergunta, mas há uma pergunta para toda resposta, e pode não haver uma solução para todo problema, mas há um problema para toda solução.

Para Boland (1994), os metodólogos que seguem o Popper ${ }_{\mathrm{D}}$ gastam a maior parte do seu tempo criando e encorajando a crítica. A ciência está corporificada num processo motivado pela crítica, e não pela perseguição de uma justificação racional.

\section{Considerações finais}

Uma análise. da forma como foi recebido o pensamento de Popper na metodologia da economia permite concluir que surgiram, com o passar do tempo, diferentes interpretações que deixaram dúvidas sobre a unidade no pensamento filosófico de Karl Popper. Blaug, por exemplo, destaca a visão do falsificacionismo 
como o método para economia. No entanto, o método falsificacionista de Popper, entendido como uma questão puramente de lógica, pode ser aplicável a todas as ciências (sejam naturais ou sociais). A metodologia na economia seria capaz de adotar o falsificacionismo, desde que conduzido como um critério de ajuizar e não de verificar teorias (como era o caso dos positivistas lógicos). Popper ressalta que seu método de falsificação não visava a provas factuais para as teorias, ou seja, era favorável apenas com a dedução no campo da lógica.

Para Hands e Caldwell, no que se refere às ciências sociais, Popper elabora um método, denominado de análise situacional ou lógica da situação, como sendo o método compreensivo-objetivo para tais ciências. Neste novo método, por sua vez, estabelece o princípio de racionalidade para excluir toda e qualquer característica psicológica das análises referentes às diferentes situaçōes dos indivíduos. O princípio de racionalidade, despojado de meios psicológicos e de características empiristas, assume a forma de um postulado metodológico que não pode ser falsificável. Entretanto, o Popper falsificacionista, para estes dois metodólogos, era incompatível com o da análise situacional. Para Caldwell, o racionalismo crítico foi a maneira encontrada por Popper para burlar este problema. Porém, a incompatibilidade destacada por Hands e Caldwell nāo aparece como preocupação de Popper, e, portanto, os metodólogos estariam atacando um problema inexistente. $\mathrm{E}$, a separação entre diferentes Popper ligados a épocas distintas, como as interpretações apresentadas no artigo sugere, pode ser tomada como pouco confiável. Popper pode ter dado diferentes ênfases aos temas ao longo de sua vida, contudo isso não implica a existência de diversos Popper.

A filosofia de Popper dificulta uma análise baseada em caricaturas popperianas conforme os diferentes períodos de sua existência. Ou seja, a filosofia popperiana não pode ser interpretada como diferentes visões em diversas épocas ou de diferentes métodos em termos de ciência natural e ciência social. $O$ que pode ser destacado da filosofia de Popper é a sua preocupação com a atitude crítica na pesquisa científica. Para Popper, o racionalismo crítico é entendido como uma forma de pensar ou até mesmo um modo de vida, desde que represente uma disposição para ouvir argumentos críticos, procurar os próprios erros e aprender com eles. Isso é uma atitude que Popper tentou formular pela primeira vez em 1932 na seguinte afir- 
mação: "eu posso estar errado e você pode estar certo, e por um esforço poderemos nos aproximar da verdade" (Popper, 1994, p. xii). Esta postura pode ser entendida como uma forma de enfrentar os problemas, estando o cientista sempre aberto às criticas e discussões e, tendo o realismo objetivo como pano de fundo. A filosofia de Popper mostra a existência de uma única pessoa e isso pode ser entendido mais claramente com a abordagem do Popper socrático. Este artigo, porém, não discute se esta visão é estritamente popperiana, mas que apenas pode ser utilizada para expressar, de uma forma geral, a unidade no pensamento do filósofo.

A ciência, na abordagem do Popper $_{\mathrm{D}}$, caracteriza um espaço de debate crítico acerca dos resultados obtidos com os diferentes modelos explicativos. Nesta perspectiva, os princípios utilizados pelos modelos, como aqueles adotados na economia, direcionados aos diversos contextos são importantes. Mas, também é, especialmente interessante, a discussão crítica dos resultados derivados destes modelos, desde que conduzida nas linhas do falsificacionismo e do racionalismo crítico. Portanto, o que aparece como distinto, nas diferentes épocas, são os temas discutidos por Popper, mas não sua forma de pensamento enquanto epistemólogo e filósofo da Ciência.

\section{Referências Bibliográficas}

BLAUG, Mark. (1999) [1983] Metodologia da economia: ou como os economistas explicam. Trad. Afonso Santos Lima. São Paulo: Edusp.

(1994). "Why I am not a constructivist. Confessions of an unrepentant Popperian". In: BACKHOUSE, Roger E.(ed.) (1994). New Directions in Economic Methodology. London: Routledge, 109-36.

BOLAND, Lawrence (1994). "Scientific thinking without scientific method: two views of Popper". In: BACKHOUSE, Roger E.(ed.) (1994). New Directions in Economic Methodology. London: Routledge, 154-72.

CALDWELL, Bruce (1991). "Clarifying Popper". Journal of Economic Literature, 29 (1):1-33.

FRIEDMAN, Milton (1981) [1953]. "A Metodologia da Economia Positiva". Edições Multiplic, Vol. 1, № 3. (Trad. Leônidas Hegenberg)

HANDS, D. Wade. (1992). "Falsification, Situational Analysis and Scientific Research Programs: The Popperian Tradition in Economic Methodology". In De Marchi, Neil (ed.). Post-Popperian Methodology of Economics: Recovering Practise. Boston/Dordrecht/ London: Kluwer Academic Publishers. 
LAKATOS, Imre. (1979) [1970]. "O falseamento e a metodologia dos programas de pesquisa científica”. In: LAKATOS, Imre e Alan MUSGRAVE, A crítica e o Desenvolvimento do Conhecimento. Trad. Octávio Mendes Cajado. São Paulo: Cultrix, 109-243.

NEIVA, Eduardo. (1999). O Racionalismo Crítico de Popper. Francisco Alves: Rio de Janeiro.

ZAHAR, E. G. "O problema da base empírica". In: O`HEAR, Anthony (org.). (1997). Karl Popper: Filosofia e Problemas. São Paulo : Unesp.

POPPER, Karl R. (1974) [1934] A Lógica da Pesquisa Científica. São Paulo: Cultrix. (1974) [1945] A Sociedade Aberta e Seus Inimigos. São Paulo : Unesp. Trad. Milton Amado.

(1992) [1961] "A Lógica das Ciências Sociais". In: POPPER, Karl. Em Busca de um Mundo Melhor. Lisboa: Fragmentos.

(1995) [1967] "El Principio de Racionalidad". In:. MILLER, David (comp.) Popper Escritos Selectos. México: Fondo de Cultura Económica. Trad. Sergio René Madero Báez.

(1997) [1982] ORealismo e o Objetivo da Ciência: Pós-Escrito à Lógica da Descoberta Científica. Lisboa : Dom Quixote.

(1994) The Myth of the Framework. In defence of science and rationality. London: Routledge. 